\title{
Mechanisms of a Cyclobutane-Fused Lactone Hydrolysis in Alkaline and Acidic Conditions
}

\author{
Zhangxia Wang and Haibo Ma *D
}

check for

updates

Citation: Wang, Z.; Ma, H.

Mechanisms of a Cyclobutane-Fused Lactone Hydrolysis in Alkaline and

Acidic Conditions. Molecules 2021, 26, 3519. https://doi.org/10.3390/ molecules26123519

Received: 11 May 2021

Accepted: 8 June 2021

Published: 9 June 2021

Publisher's Note: MDPI stays neutral with regard to jurisdictional claims in published maps and institutional affiliations.

Copyright: (c) 2021 by the authors. Licensee MDPI, Basel, Switzerland. This article is an open access article distributed under the terms and conditions of the Creative Commons Attribution (CC BY) license (https:// creativecommons.org/licenses/by/ $4.0 /)$.
Jiangsu Key Laboratory of Vehicle Emissions Control, School of Chemistry and Chemical Engineering, Nanjing University, Nanjing 210023, China; wangzhangxia@smail.nju.edu.cn

* Correspondence: haibo@nju.edu.cn; Tel.: +86-25-89685680

Abstract: Searching for functional polyesters with stability and degradability is important due to their potential applications in biomedical supplies, biomass fuel, and environmental protection. Recently, a cyclobutane-fused lactone (CBL) polymer was experimentally found to have superior stability and controllable degradability through hydrolysis reactions after activation by mechanical force. In order to provide a theoretical basis for developing new functional degradable polyesters, in this work, we performed a detailed quantum chemical study of the alkaline and acidic hydrolysis of CBL using dispersion-corrected density functional theory (DFT-D3) and mixed implicit/explicit solvent models. Various possible hydrolysis mechanisms were found: $\mathrm{B}_{\mathrm{AC}} 2$ and $\mathrm{B}_{\mathrm{AL}} 2$ in the alkaline condition and $\mathrm{A}_{\mathrm{AC}} 2, \mathrm{~A}_{\mathrm{AL}} 2$, and $\mathrm{A}_{\mathrm{AL}} 1$ in the acidic condition. Our calculations indicated that $\mathrm{CBL}$ favors the $\mathrm{B}_{\mathrm{AC}} 2$ and $\mathrm{A}_{\mathrm{AC}} 2$ mechanisms in alkaline and acidic conditions, respectively. In addition, we found that incorporating explicit water solvent molecules is highly necessary because of their strong hydrogen-bonding with reactant/intermediate/product molecules.

Keywords: hydrolysis mechanisms; cyclobutane-fused lactone; DFT; solvation model

\section{Introduction}

Recently, a cyclobutane-fused lactone (CBL) polymer was proposed and demonstrated to have superior stability and controllable degradability [1]. Cyclobutane shows a perfect stability to keep the polymer's backbone when the ester groups are hydrolyzed under alkaline and acidic conditions. When degradation is needed, the CBL polymer can be degraded through hydrolysis reactions after activation by mechanical force (Scheme 1). Hopefully, functional materials with degradability and stability will be developed based on the special chemical structure of CBL, especially in biomedical applications, but there have been no relevant research reports so far. At the same time, theoretical research on the hydrolysis mechanism of CBL is lacking. In order to provide the basis for the application of CBL polymer materials, we need to unravel its hydrolysis mechanisms.

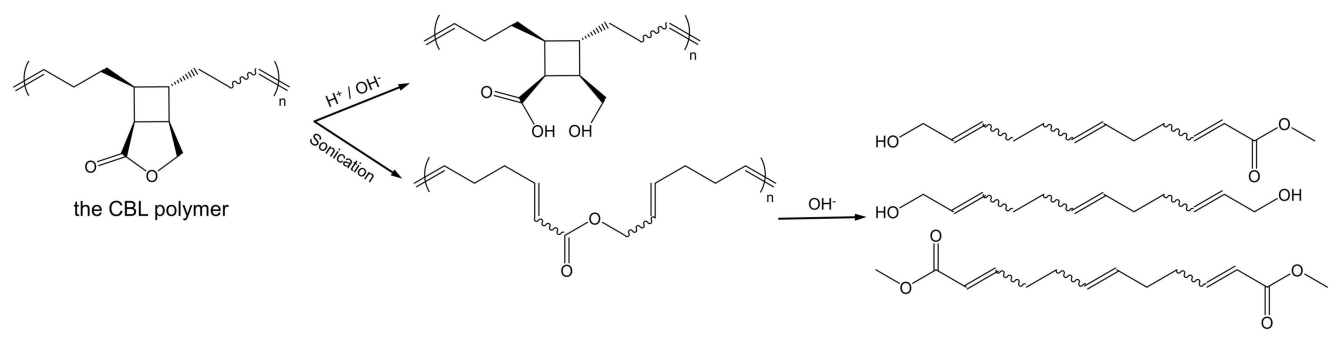

Scheme 1. The cyclobutane-fused lactone (CBL) polymer (i) hydrolysis in alkaline or acidic conditions and (ii) mechanochemical activation after sonication.

The hydrolysis mechanisms of CBL are complex, and there are different reaction routes in different chemical environments. Solvent molecules also have a great influence on the 
hydrolysis reaction, because water molecules play more than one role in hydrolysis: acting as solvent, proton-carrier, and catalyst. Moreover, there are strong hydrogen-bonding interactions between water molecules and reactant/intermediate/product molecules that cannot be ignored in the study of the reaction mechanism [2]. Therefore, it is necessary to study the functions of explicit solvent molecules and the influence of various numbers of water molecules in detail.

Lactone hydrolysis has been widely studied in organic chemical experiments and biological systems. A comprehensive theoretical calculation work by Gómez-Bombarelli et al., summarized the features of the various possible hydrolysis mechanisms of two linear esters and eight lactones [3,4]. In this work, they directly adopted a model of one ester molecule including six water molecules. Though employing explicit solvation models is reliable for studying reaction mechanisms [5-13], they ignored the effect of a varying number of water molecules on the hydrolysis processes. CBL is similar to lactones in structure, so it features all the possible hydrolysis mechanisms of lactones. Compared with $\gamma$-butyrolactone, CBL has one more cyclobutane in its chemical structure, which may affect its hydrolysis mechanism.

In this work, the hydrolysis mechanisms of CBL were investigated by density functional theory (DFT) calculations with explicit solvation models. The classification of ester hydrolysis mechanisms proposed by Ingold [14] was adopted: the capital letters A and B stand for acid- and base-catalyzed, respectively; the subscripts $\mathrm{AC}$ and $\mathrm{AL}$ stand for acylor alkyl-oxygen cleavage, respectively; and the last numbers 1 and 2 stand for the uni- or bimolecular pathway, respectively. A detailed comparison of CBL hydrolysis with pure implicit solvent and mixed implicit/explicit solvent models was discussed. The calculation results showed that $\mathrm{CBL}$ follows $\mathrm{B}_{\mathrm{AC}} 2$ (activation free energy, $\Delta G^{\neq}=15.4 \mathrm{kcal} / \mathrm{mol}$ ) and $\mathrm{A}_{\mathrm{AC}} 2\left(\Delta G^{\neq}=24.2 \mathrm{kcal} / \mathrm{mol}\right)$ mechanisms in alkaline and acidic conditions, respectively. $\mathrm{B}_{\mathrm{AC}} 2$ (base catalyzed nucleophilic addition followed by hydrolysis) and $\mathrm{A}_{\mathrm{AC}} 2$ (acid catalyzed hydrolysis) mechanisms are the two most important pathways in ester hydrolysis in practice, and both of them proceed via a tetrahedral intermediate [15]. $\mathrm{A}_{\mathrm{AL}} 1$ has been rarely reported, and we also found that it is unlikely to occur because of a high activation free energy of $37.1 \mathrm{kcal} / \mathrm{mol}$. At the same time, our calculations indicated that using a purely implicit solvation model will underestimate activation free energies by $\sim 4 \mathrm{kcal} / \mathrm{mol}$ in $\mathrm{B}_{\mathrm{AC}} 2$ when compared with incorporating additional explicit water solvent molecules, and the activation free energies will not change much when including more than two explicit water molecules.

\section{Computational Details}

Quantum chemical calculations based on dispersion-corrected DFT [16] were performed using Gaussian 16 Rev. A.03. [17] The geometries of reactants (R), transition states (TS), intermediates (Int), and products (P) were optimized with no constraints at the B3LYP$\mathrm{D} 3 / 6-311+\mathrm{G}(\mathrm{d})$ level [18] for studying the basic hydrolysis, whereas the $6-311++G(d, p)$ basis set was used to obtain the stationary points under the acidic condition. Solvent model density (SMD) [19] was selected to account for the contribution of solvation free energy to the total energy. The B3LYP-D3/6-311+G(d) theory level has been used for similar systems like the alkaline hydrolysis reaction of $\gamma$-butyrolactone [3,4], and the difference in activation free energy was found to be $0.1 \mathrm{kcal} / \mathrm{mol}$ at B3LYP-D3/6-311++G(2df,pd) level (Table S1). We also tested the M06-2X functional, and Tables S1 and S2 in the Supplementary Materials show that using B3LYP-D3 could get results that were consistent with the experiment for the alkaline hydrolysis reaction of $\gamma$-butyrolactone. Free energies were obtained relative to the $\mathrm{R}$ of each pathway, and the lowest energy $\mathrm{R}$ was chosen as a reference.

A common approach for including specific solute-solvent interactions is the use of a combination of dielectric continuum and explicit solvent molecules [11], an approach that has been called discrete-continuum [20], cluster-continuum [21], or implicit/explicit solvation [22]. Using this approach is effective to describe chemical reactions in aqueous solutions - particularly the hydrolysis reactions of amides [23-29], phosphates [7,30-34], 
and esters [3-6,35-38]. Therefore, we used the implicit/explicit solvation model to consider solvent effects for the CBL hydrolysis reaction. Stationary points (R/TS/Int/P) were optimized with the addition of 0-6 water molecules to the system. The water molecules were added one-by-one by hand in the initial structure, thus ensuring that each water molecule was not isolated. Additional water molecules of each transition state were added near the nucleophile group, the leaving group, and the CBL oxygen atoms. Another situation where water molecules could form hydrogen bonds with each other to stabilize the structures was also considered. In short, the additional water molecules should form more than one hydrogen bond with adjacent molecules. All the structures were reoptimized, and thermochemical values were computed at a room temperature of $298 \mathrm{~K}$ using uncorrected frequencies. The intrinsic reaction coordinate (IRC) paths [39] connecting the reactants and products were calculated to ensure that the transition states were reliable. The Cartesian coordinates and SCF energies of all optimized stationary points are provided in the Supplementary Materials. Because the CBL hydrolysis reactions are reversible and multiple, the Gibbs energy of activation $\Delta G^{\neq}$derived from experiment $[18,40]$ was given by Equation (1):

$$
\Delta G^{\neq}=\Delta G_{T S 1}+\Delta G_{T S 2}-\Delta G_{I n t}+R T \ln \left(e^{-\frac{\Delta G_{T S 2}-\Delta G_{I n t}}{R T}}+e^{-\frac{\Delta G_{T S 1}-\Delta G_{I n t}}{R T}}\right)
$$

\section{Results and Discussion}

\subsection{Alkaline Hydrolysis}

As shown in Scheme 2, there are two base-catalyzed mechanisms of CBL hydrolysis: $\mathrm{B}_{\mathrm{AC}} 2$ and $\mathrm{B}_{\mathrm{AL}} 2$. The $\mathrm{B}_{\mathrm{AC}} 2$ mechanism can be divided into two steps: the addition step and the elimination step. The nucleophile $\mathrm{OH}^{-}$attacks the carbonyl carbon to form a tetrahedral intermediate (Int), and then the acyl-oxygen bond breaks before a process of intermolecular proton transfer $\left(\mathrm{H}_{2} \mathrm{O}\right.$ attacks the ether $\left.\mathrm{O}\right)$. In the $\mathrm{B}_{\mathrm{AL}} 2$ mechanism, the $\mathrm{OH}^{-}$attacks the alkoxyl carbon from the opposite direction and the alkyl-oxygen bond is damaged at the same time.
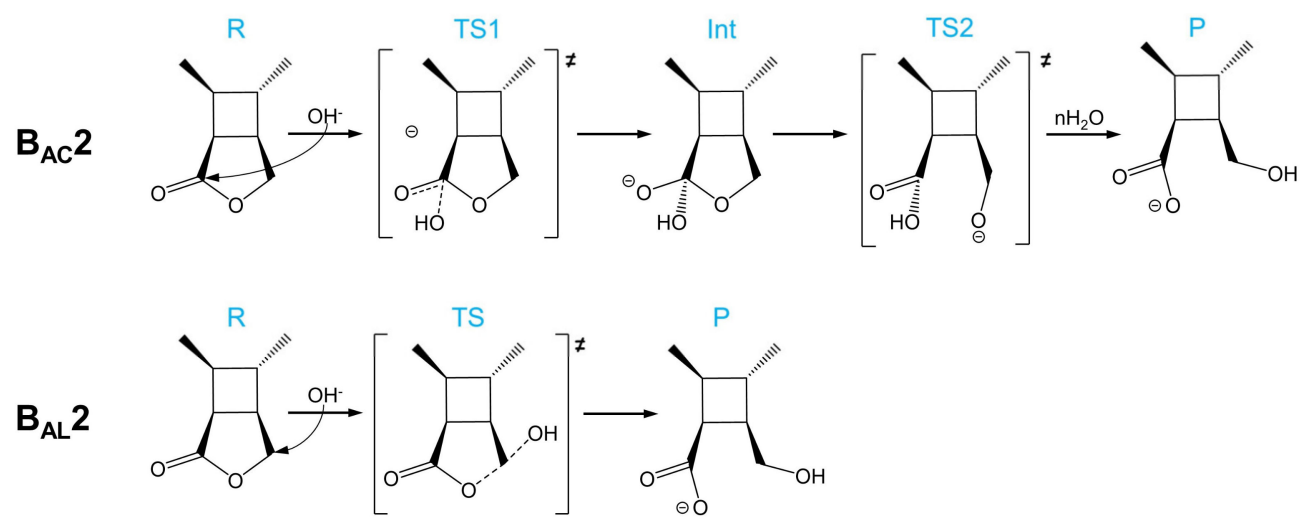

Scheme 2. $\mathrm{B}_{\mathrm{AC}} 2$ and $\mathrm{B}_{\mathrm{AL}} 2$ mechanisms of the alkaline hydrolysis of $\mathrm{CBL}$.

\subsubsection{The $\mathrm{B}_{\mathrm{AC}} 2$ Mechanism: Deeper Insight by Explicit Solvent Models}

In recent years, it has become popular to model ester hydrolysis and other reactions by adopting mixed implicit/explicit solvent models, which are especially useful in reactions involving ionic species [7]. To investigate whether the explicit solvent molecules had a substantial impact on the energies and geometries of the optimized stationary points, we performed geometrical optimizations for the $\mathrm{B}_{\mathrm{AC}} 2$ mechanism pathway of $\mathrm{CBL}$ with 0-6 water molecules using B3LYP-D3/6-311+G(d) in SMD. It is difficult to calculate all the microsolvated isomers and conformers for R, TS1, Int, and TS2 of CBL, especially when more and more water molecules are added to the system. Our strategy was to choose the configuration with the lowest energy for the following discussion. Here, TS1 was the transition state of the addition step, and TS2 was the transition state of the elimination step. Because the relative free energies of TS1, Int, and TS2 were based on R, we chose the 
$\mathrm{R}$ conformations carefully. We manually placed the water molecules to make the system form as many as hydrogen bonds as possible, and in this way, we chose the lowest energy conformation. Another method for choosing the lowest energy conformation was to locate the possible reactant complex following the IRC and then reoptimize it. Finally, compared the values obtained by the two ways and selected the one with the lowest energy. We found that the water molecules and $\mathrm{OH}^{-}$gathered together to form a cluster.

The results of the $\mathrm{B}_{\mathrm{AC}} 2$ reaction path of $\mathrm{CBL}$ with varying numbers of water molecules are shown in Figure 1 and Table 1. From these data, it can be seen that the relative free energies of TS1, Int, and TS2 were all the smallest when no water molecules were included, resulting in the smallest activation free energy $\left(\Delta G^{\neq}=12.6 \mathrm{kcal} / \mathrm{mol}\right)$, followed by the presence of only one water molecule $\left(\Delta G^{\neq}=13.3 \mathrm{kcal} / \mathrm{mol}\right)$. When the number of water molecules added to the model was greater than one, the relative free energies of the stationary points were almost the same and the calculated activation free energies were in the range of $15.7-16.6 \mathrm{kcal} / \mathrm{mol}$. From this, we got an average activation free energy of $15.4 \pm 2.8 \mathrm{kcal} / \mathrm{mol}$. This indicated that incorporating explicit water solvent molecules is highly necessary because of their strong hydrogen-bonding with reactant/intermediate/product molecules. For example, water molecules formed hydrogen bonds with $\mathrm{OH}^{-}$and the alkoxyl oxygen and carbonyl oxygen of CBL (Figure 2). After placing six explicit water molecules, the $\Delta G^{\neq}$of the $B_{A C} 2$ reaction path converged to average value. Therefore, we did not add further water molecules.

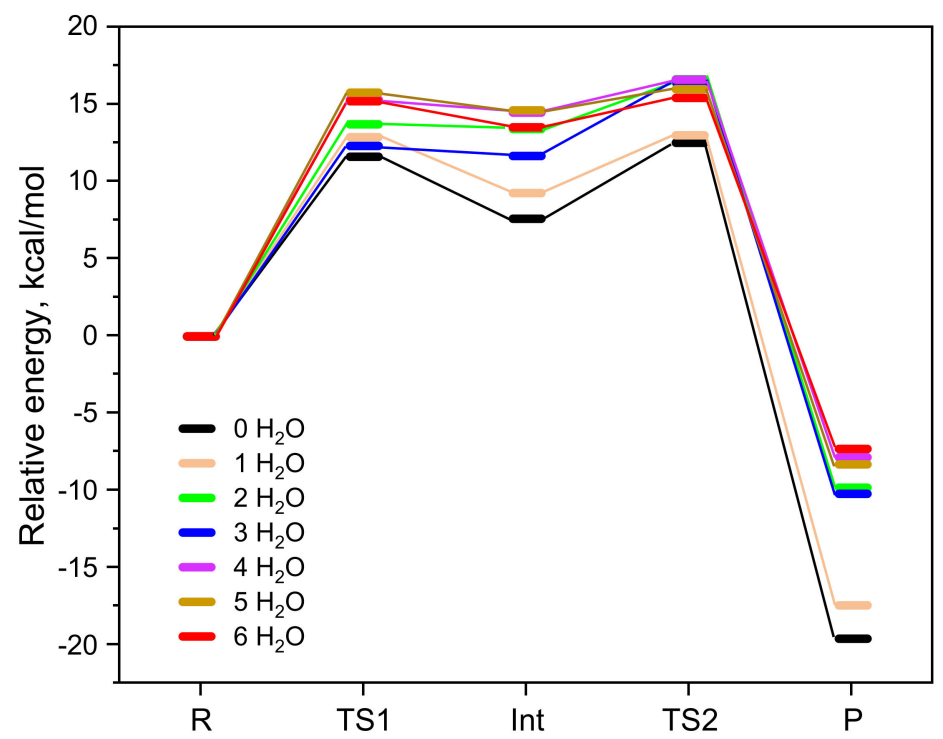

Figure 1. Comparison of the results of the $\mathrm{B}_{\mathrm{AC}} 2$ reaction path of $\mathrm{CBL}$ without microsolvation and with 1-6 $\mathrm{H}_{2} \mathrm{O}$ molecules. Free energies of TS1, Int, TS2, and P are relative to the $\mathrm{R}$ of each pathway.

Table 1. Relative free energies and the corresponding activation free energies $\left(\Delta G^{\neq}\right)$of the $B_{A C} 2$ reaction path of CBL with 0-6 $\mathrm{H}_{2} \mathrm{O}$ molecules. Free energies of TS1, Int, and TS2 are relative to the $\mathrm{R}$ of each pathway. Energies are presented in $\mathrm{kcal} / \mathrm{mol}$.

\begin{tabular}{ccccc}
\hline System & TS1 & Int & TS2 & $\Delta \boldsymbol{G}^{\neq}$ \\
\hline $0 \mathrm{H}_{2} \mathrm{O}$ & 11.6 & 7.6 & 12.5 & 12.6 \\
$1 \mathrm{H}_{2} \mathrm{O}$ & 12.9 & 9.3 & 13.0 & 13.3 \\
$2 \mathrm{H}_{2} \mathrm{O}$ & 13.7 & 13.4 & 16.6 & 16.6 \\
$3 \mathrm{H}_{2} \mathrm{O}$ & 12.3 & 11.7 & 16.4 & 16.4 \\
$4 \mathrm{H}_{2} \mathrm{O}$ & 15.3 & 14.5 & 16.6 & 16.6 \\
$5 \mathrm{H}_{2} \mathrm{O}$ & 15.7 & 14.6 & 16.0 & 16.3 \\
$6 \mathrm{H}_{2} \mathrm{O}$ & 15.2 & 13.5 & 15.4 & 15.7 \\
\hline
\end{tabular}




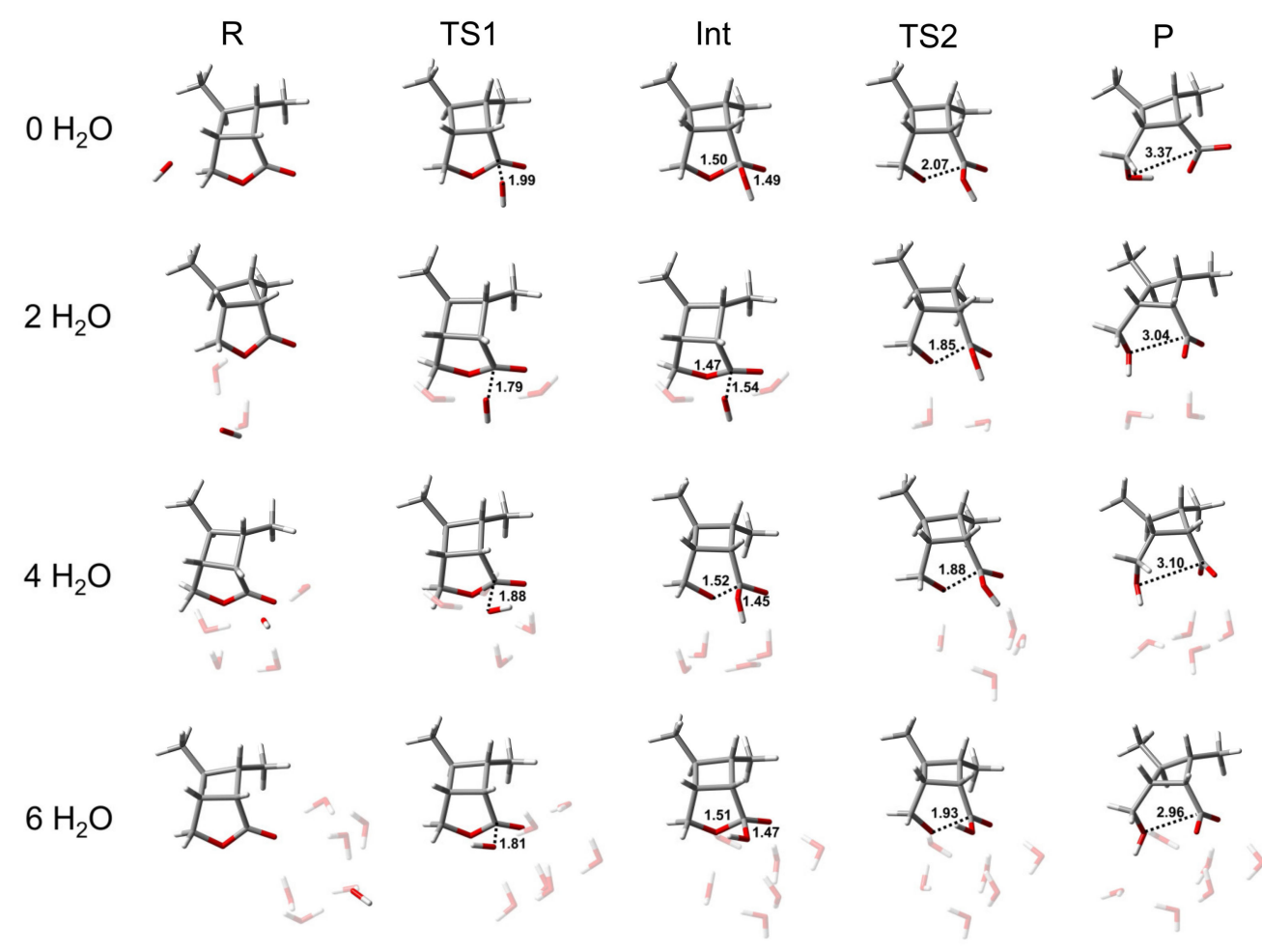

Figure 2. Representative structures of $\mathrm{R}, \mathrm{TS} 1$, Int, TS2, and $\mathrm{P}$ of the $\mathrm{B}_{\mathrm{AC}} 2$ reaction path of CBL, with varying numbers of $\mathrm{H}_{2} \mathrm{O}$ molecules. The unit of distance is $\AA$. The coordinates of all optimized stationary points are provided in the Supplementary Materials.

While the energetics of the $\mathrm{B}_{\mathrm{AC}} 2$ reaction did not seem to be remarkably affected by the inclusion of the water molecules $\left(>2 \mathrm{H}_{2} \mathrm{O}\right)$, the explicit solvent effect for the transition state geometries was significant. Adding an increasing number of explicit water molecules to the $\mathrm{B}_{\mathrm{AC}} 2$ reaction tightened the transition state by up to 0.18 or $0.25 \AA$ in the $\mathrm{C}-\mathrm{O}_{\text {nuc }}$ or $\mathrm{C}-\mathrm{O}_{\mathrm{lg}}$ distance, respectively (In Figure 2 and Table S3, C-O $\mathrm{O}_{\text {nuc }}$ or $\mathrm{C}-\mathrm{O}_{\mathrm{lg}}$ denotes the bond lengths to the nucleophile or leaving group). This illustrates that TS1 and TS2 are better solvated by adding explicit water molecules to introduce hydrogen-bonding interactions. Similar changes also appeared in the product. The $\mathrm{C}-\mathrm{O}_{\mathrm{lg}}$ distance of the product reduce from $3.37 \AA$ (no water molecules are present) to $2.96 \AA$ (six water molecules are present), i.e., a reduction of around $12 \%$. For the intermediate, the bond lengths of $\mathrm{C}-\mathrm{O}_{\text {nuc }}$ and $\mathrm{C}-\mathrm{O}_{\lg }$ did not change.

In our calculations, we found that when there was no or only one water molecule in the model, we got the transition state of intramolecular proton transfer (as shown in Figure S1 in the Supplementary Materials). The relative free energy of the proton transfer step was $13.0 \mathrm{kcal} / \mathrm{mol}$ when no water molecules were present and $17.3 \mathrm{kcal} / \mathrm{mol}$ when one water molecule was present, and both were higher than the energy barriers of the nucleophilic addition and the leaving group departure. Therefore, the intramolecular proton transfer was unfavorable in terms of energy within this approximation. Furthermore, the intramolecular proton transfer never happened in alkaline conditions. In fact, the proton may transfer through multiple water molecules to achieve the deprotonation of the nucleophile and protonation of the leaving group. However, it would have been too computationally consuming to explore the full proton transfer network. Additionally considering the proton transfer step is usually not rate-limiting in the base-catalyzed hydrolysis of lactones [3] and phthalate esters [7,38], in this work, we did not investigate the intermolecular proton transfer in detail, but the tendency of protonation of the leaving group was observed in the IRC results (see Figure S2). This showed that the intermolecular proton transfer was spontaneous. Meanwhile, a relaxed potential energy surface scan was performed to estimate the deprotonation and protonation barrier of $\mathrm{CBL}+6 \mathrm{H}_{2} \mathrm{O}+\mathrm{OH}^{-}$ 
(Figure S3). We fixed the positions of the alkyl-oxygen and the hydrogen atom of $\mathrm{H}_{2} \mathrm{O}$. The initial length of $\mathrm{O} \cdots \mathrm{HOH}$ was $1.78 \AA$, and then scan steps of $0.02 \AA$ were carried out (0.98-1.78 $\AA$ ). It can be seen from the results that the deprotonation of the nucleophile and protonation of the leaving group happened at the same time and that the electronic energy barrier $(\Delta E)$ was about $10 \mathrm{kcal} / \mathrm{mol}$.

Cyclobutane had little effect on structures of the transition state along the $\mathrm{B}_{\mathrm{AC}} 2$ reaction pathway of CBL compared to $\gamma$-butyrolactone. The only difference was that the structure of the product obtained by hydrolysis through the $\mathrm{B}_{\mathrm{AC}} 2$ pathway remained unchanged (the initial "lactone group" remained cyclic after hydrolysis; see Figure 2), while the product of $\gamma$-butyrolactone without cyclobutane was linear [3,4]. This suggests that the reversible reaction of CBL hydrolysis is structurally advantageous compared to $\gamma$-butyrolactone, and this feature is expected to develop CBL polymers that can achieve industrial recyclability. Table S4 presents the dihedral angles (C-C-C-C) to the cyclobutane at each stationary point. No matter how many water molecules were added to the model, the cyclobutane in the products was twisted and the dihedral angles increased by $8^{\circ}$.

\subsubsection{The $\mathrm{B}_{\mathrm{AL}} 2$ Mechanism}

From the analysis of the $\mathrm{B}_{\mathrm{AC}} 2$ reaction pathway, it could be seen that the number of water molecules did not have a great influence on the hydrolysis mechanism and the energy barrier. Here, we used a model containing six water molecules $\left(\mathrm{CBL}+6 \mathrm{H}_{2} \mathrm{O}+\mathrm{OH}^{-}\right)$for the following discussion. Figure 3 shows the structures of $R, T S$, and $P$ of the $B_{A L} 2$ reaction path. TS corresponds to the single-step hydrolysis reaction in which nucleophilic attack and alkyl-oxygen cleavage occur simultaneously (similar to $S_{N} 2$ nucleophilic substitution reaction mechanism). The structure of the transition state showed that there were two water molecules forming hydrogen bonds with $\mathrm{OH}^{-}$and two water molecules forming hydrogen bonds with alkoxyl oxygen and carbonyl oxygen. The remaining two water molecules were not connected to CBL, as they were only hydrogen-bonding to several water molecules. The bond distances of $\mathrm{C}-\mathrm{O}_{\text {nuc }}$ and $\mathrm{C}-\mathrm{O}_{\mathrm{lg}}$ were 2.14 and $1.94 \AA$. The activation energy barrier of the reaction was $24.6 \mathrm{kcal} / \mathrm{mol}$, which was $9 \mathrm{kcal} / \mathrm{mol}$ higher than that of the $\mathrm{B}_{\mathrm{AC}} 2$ pathway (Figure 4), indicating that the alkaline hydrolysis reaction of $\mathrm{CBL}$ tended to proceed along $\mathrm{B}_{\mathrm{AC}} 2$. In addition, the $\mathrm{C}$ adjacent to ether $\mathrm{O}$ was sp $\mathrm{sp}^{3}$ hybrid and less positive charged than the ketonic $C$, which indicated that $B_{A L} 2$ is less likely to occur. We could directly obtain the stable product (P in Figure 3 ) through the $\mathrm{B}_{\mathrm{AL}} 2$ hydrolysis pathway without proton transfer happening.

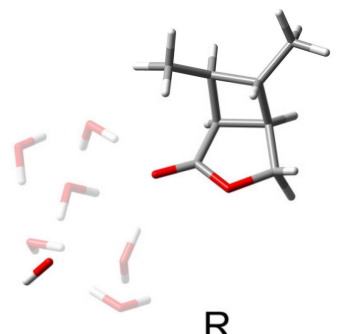

$\mathrm{R}$

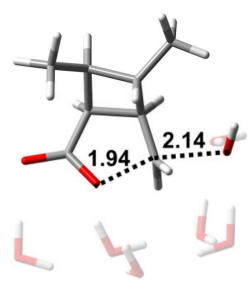

TS

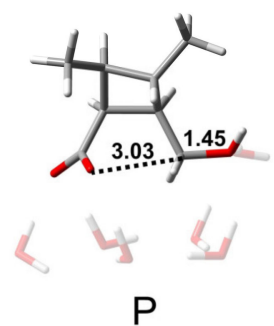

$\mathrm{P}$

Figure 3. Structures of $\mathrm{R}$, $T S$, and $\mathrm{P}$ of $\mathrm{B}_{\mathrm{AL}} 2$ reaction path of $\mathrm{CBL}$ with $6 \mathrm{H}_{2} \mathrm{O}$ molecules. The unit of distance is $\AA$. 


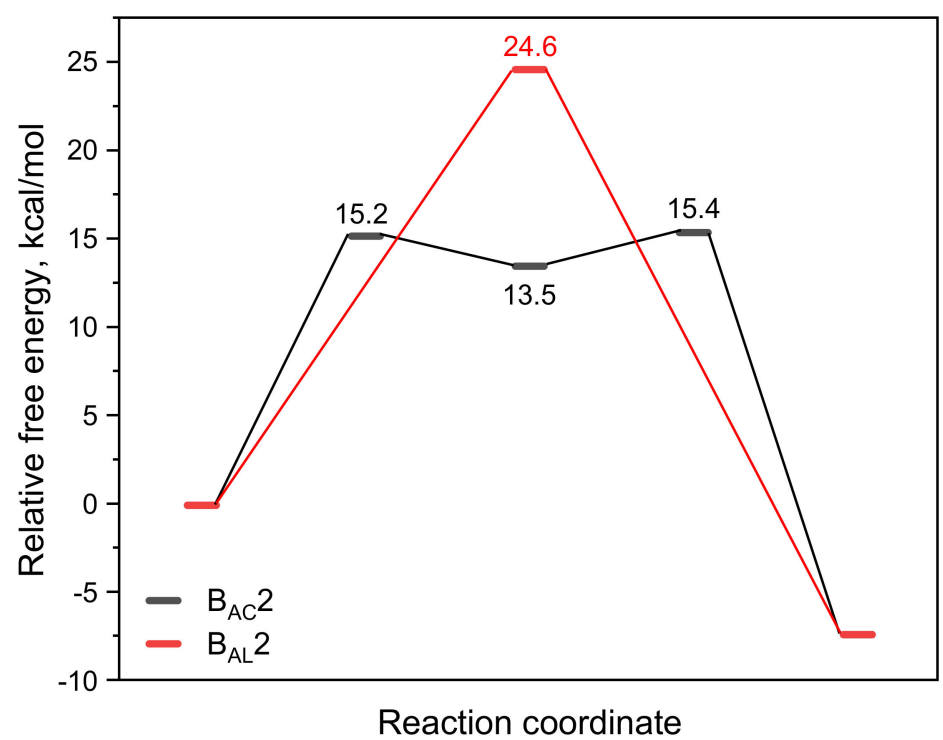

Figure 4. Variation in the relative free energy $(\Delta G)$ along the $\mathrm{B}_{\mathrm{AC}} 2$ and $\mathrm{B}_{\mathrm{AL}} 2$ reaction paths for the alkaline hydrolysis of CBL.

\subsection{Acidic Hydrolysis}

As shown in Scheme 3, there are three acid-catalyzed mechanisms of CBL hydrolysis: $\mathrm{A}_{\mathrm{AC}} 2, \mathrm{~A}_{\mathrm{AL}} 2$, and $\mathrm{A}_{\mathrm{AL}} 1$. The $\mathrm{A}_{\mathrm{AC}} 2$ mechanism is generally considered to be the most favorable mechanism in acidic conditions: the carbonyl oxygen is protonated, one water molecule acts as a nucleophile to attack the acyl-carbon, and finally the acyl-oxygen bond is broken to form a product. The activation free energy of $\mathrm{A}_{\mathrm{AC}} 2$ was found to be $24.2 \mathrm{kcal} / \mathrm{mol}$ (Scheme 3 and Figure 5). Because the protonation and deprotonation processes in the reaction are not rate-limiting steps, we focused on the two transition states (TS1 and TS2) that affect the activation free energy. In the $\mathrm{A}_{\mathrm{AL}} 2$ mechanism, one water molecule attacks the alkyl-carbon, and the alkoxy bond is simultaneously broken to obtain the pre-product. The activation free energy of this mechanism was found to be $27.0 \mathrm{kcal} / \mathrm{mol}$, which was slightly higher than that of $\mathrm{A}_{\mathrm{AC}} 2$. The least likely to occur was found to be the $\mathrm{A}_{\mathrm{AL}} 1$ mechanism. The energy barriers of both the cleavage step and the addition step were quite high, and the activation free energy of the entire reaction was $37.1 \mathrm{kcal} / \mathrm{mol}$. The $\mathrm{A}_{\mathrm{AL}} 1$ and $\mathrm{A}_{\mathrm{AL}} 2$ mechanisms were obviously not feasible at room temperature.

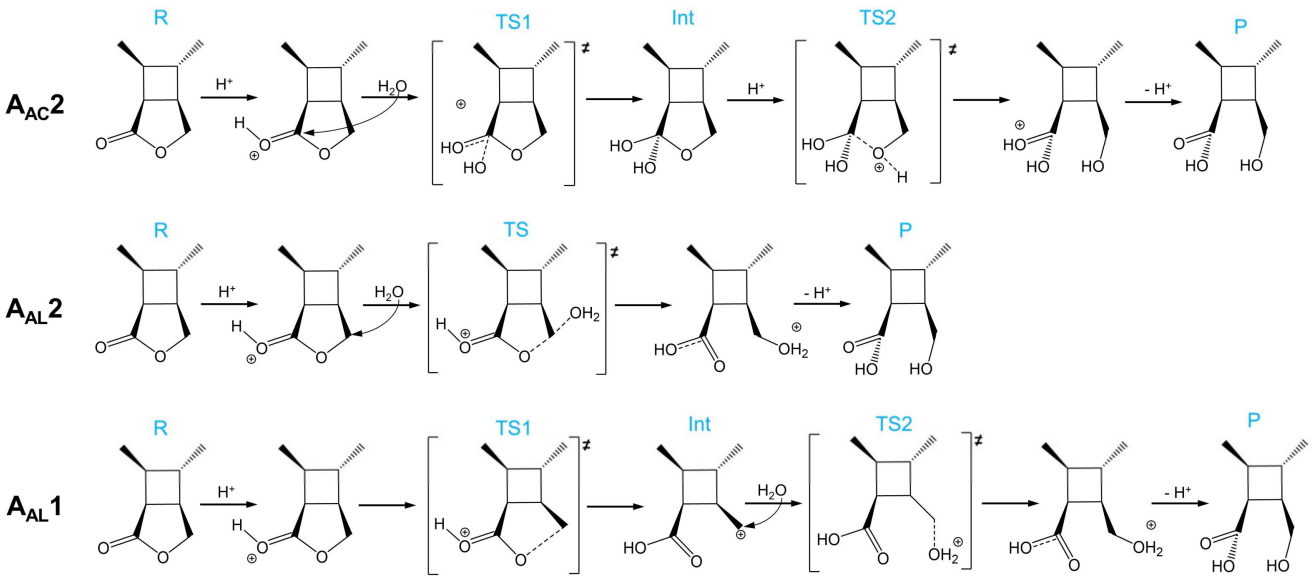

Scheme 3. $\mathrm{A}_{\mathrm{AC}} 2, \mathrm{~A}_{\mathrm{AL}}$ 2, and $\mathrm{A}_{\mathrm{AL}} 1$ mechanisms of the acidic hydrolysis of CBL. 


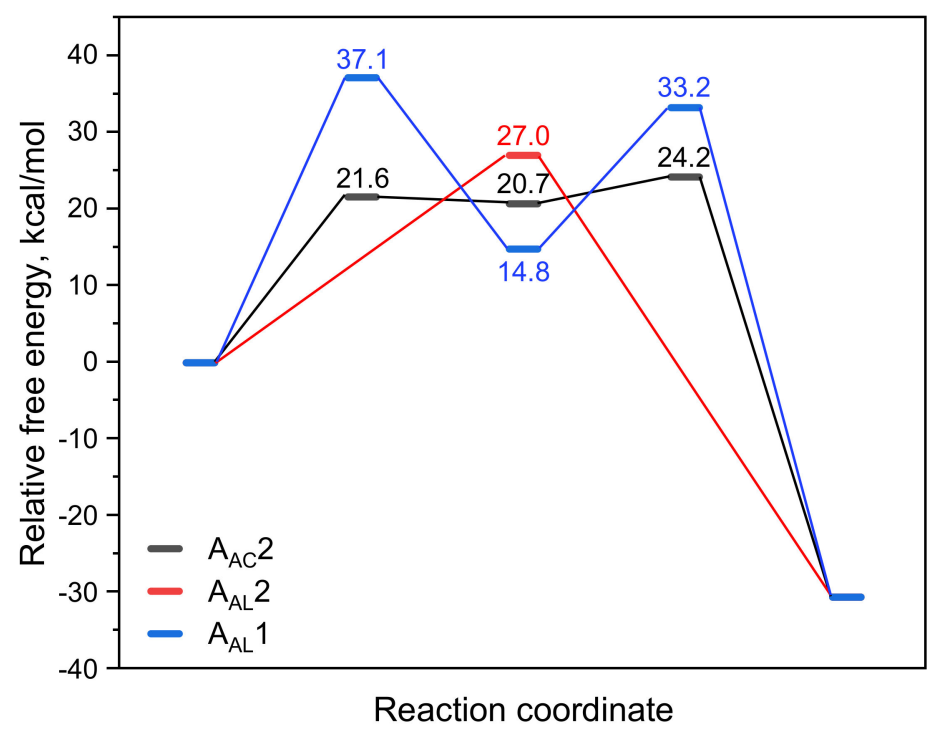

Figure 5. Variation in the relative free energy $(\Delta G)$ along the $\mathrm{A}_{\mathrm{AC}} 2, \mathrm{~A}_{\mathrm{AL}} 2$, and $\mathrm{A}_{\mathrm{AL}} 1$ reaction paths for the acidic hydrolysis of CBL.

We did not find the transition state of the $\mathrm{A}_{\mathrm{AC}} 1$ mechanism in our calculations, but we tried to fix the positions of the carbonyl carbon and the alkyl-oxygen to do a relaxed potential energy surface scan (Figure S4). The initial length of $\mathrm{C} \cdots \mathrm{O}(\mathrm{H})$ was $1.38 \AA$, and then scan steps of $0.02 \AA$ were carried out $(1.38-2.38 \AA$ ). It can be seen from the results that the rupture of the acyl-oxygen bond was accompanied by the protonation of the alkyl-oxygen. The distance of C-O changed from 1.38 to $2.38 \AA$, and the distance between alkyl-oxygen and $\mathrm{H}^{+}$changed from 1.76 to $0.99 \AA$. The electronic energy barrier $(\Delta E)$ required for the $\mathrm{A}_{\mathrm{AC}} 1$ mechanism was about $28 \mathrm{kcal} / \mathrm{mol}$ without any thermal correction.

Here, we use $\mathrm{CBL}+5 \mathrm{H}_{2} \mathrm{O}+\mathrm{H}_{3} \mathrm{O}^{+}$as the model to discuss the following three mechanisms: $A_{A C} 2, A_{A L} 2$, and $A_{A L} 1$. These three mechanisms are all based on the protonation of the carbonyl oxygen. The calculation level and methods can be found in the computational details section.

\subsubsection{The $\mathrm{A}_{\mathrm{AC}} 2$ Mechanism}

The $\mathrm{A}_{\mathrm{AC}} 2$ mechanism is similar to $\mathrm{B}_{\mathrm{AC}} 2$, both of which are two-step reactions: the addition step and the elimination step. Figure 6 shows the key structures in the $\mathrm{A}_{\mathrm{AC}} 2$ reaction path. In the system, $\mathrm{H}^{+}$ions are not independent; most of the $\mathrm{H}^{+}$ions are present in $\mathrm{H}_{3} \mathrm{O}^{+}$form. TS1 is the transition state of the addition reaction of one water attacking the carbon atom, and, at the same time, the proton of the nucleophile is transferred to an adjacent water molecule. The distance of $\mathrm{C}-\mathrm{O}_{\text {nuc }}$ was found to be $1.72 \AA$, and the $\mathrm{H}-\mathrm{O}_{\text {nuc }}$ bond in the nucleophile was elongated to $1.02 \AA$. The activation free energy of this step was found to be $21.6 \mathrm{kcal} / \mathrm{mol}$ (Figure 5). Int is the tetrahedral intermediate that lays at a high energy and easy to the next reaction. TS2 is the transition state when the acyl-oxygen bond is broken, and the cleavage of the acyl-oxygen bond simultaneously occurs with the protonation of the alkyl-oxygen. The $\mathrm{C}-\mathrm{O}_{\mathrm{lg}}$ bond length was found to be $1.57 \AA$, and the $\mathrm{H}-\mathrm{O}_{\mathrm{lg}}$ bond length was $1.12 \AA$. The activation free energy of the second step was $3.5 \mathrm{kcal} / \mathrm{mol}$. Therefore, the elimination step was found to be the rate-limiting step. For this multiple reaction pathway, the calculated Gibbs energy of activation $\Delta G^{\neq}$derived from experiment was $24.2 \mathrm{kcal} / \mathrm{mol}$. 


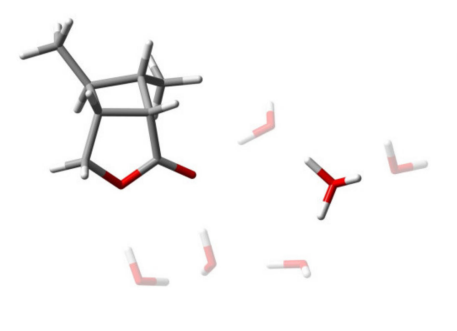

$\mathrm{R}$

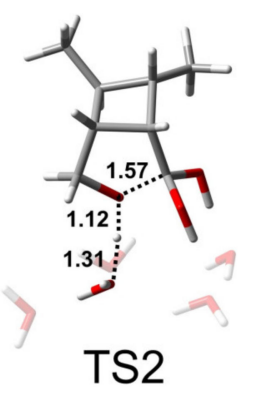

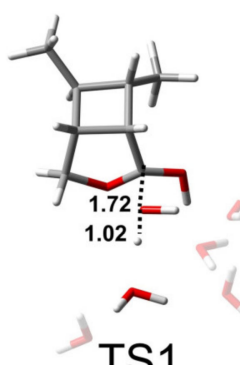

TS1

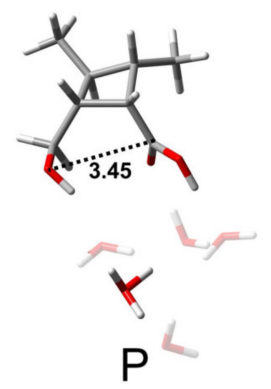

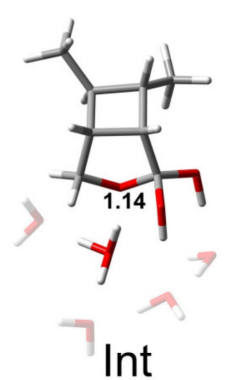

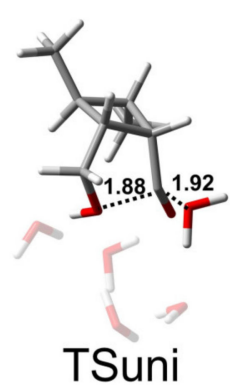

Figure 6. Structures of the stationary states of the $\mathrm{A}_{\mathrm{AC}} 2$ reaction path of $\mathrm{CBL}+5 \mathrm{H}_{2} \mathrm{O}+\mathrm{H}_{3} \mathrm{O}^{+}$. The unit of distance is $\AA$.

A single-step hydrolysis reaction $\left(\mathrm{TS}_{\text {uni }}\right.$ ), in which nucleophilic addition and acyloxygen cleavage simultaneously take place, is shown in Figure 6. This reaction pathway was higher in activation free energy than two-step reaction by about $7 \mathrm{kcal} / \mathrm{mol}$. The C- $\mathrm{O}_{\text {nuc }}$ bond length was $1.92 \AA$, and the $\mathrm{C}-\mathrm{O}_{\mathrm{lg}}$ bond length was $1.88 \AA$.

\subsubsection{The $\mathrm{A}_{\mathrm{AL}} 2$ Mechanism}

As shown in Scheme 3 and Figure 7, the $\mathrm{A}_{\mathrm{AL}} 2$ mechanism is a single-step hydrolysis reaction in which a water molecule attacks the alkyl-carbon and the alkoxy bond breaks. The bond lengths of $\mathrm{C}-\mathrm{O}_{\text {nuc }}$ and $\mathrm{C}-\mathrm{O}_{\lg }$ were found to be 2.14 and $2.01 \AA$, respectively. Similarly, water molecules are distributed around the reaction site and form hydrogen bonds with key groups. The reaction energy barrier of this pathway was found to be $27.0 \mathrm{kcal} / \mathrm{mol}$.

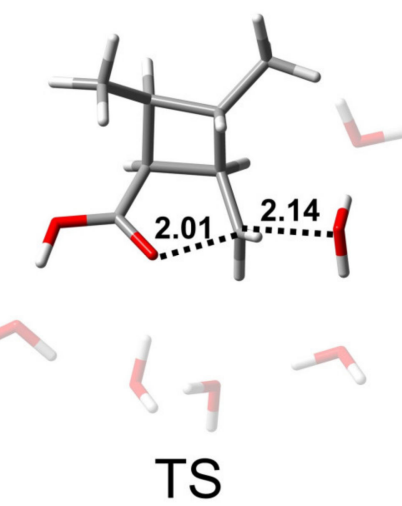

Figure 7. Structure of the transition state of the $\mathrm{A}_{\mathrm{AL}} 2$ reaction path of $\mathrm{CBL}+5 \mathrm{H}_{2} \mathrm{O}+\mathrm{H}_{3} \mathrm{O}^{+}$. The unit of distance is $\AA$.

\subsubsection{The $\mathrm{A}_{\mathrm{AL}} 1$ Mechanism}

As shown in Scheme 3 and Figure 8, the $\mathrm{A}_{\mathrm{AL}} 1$ mechanism is a two-step hydrolysis reaction: the elimination step and the addition step. Firstly, the alkoxy bond is broken, and a proton on the cyclobutane transfers to the alkyl-carbon to obtain the intermediate (Int). The $\mathrm{C}-\mathrm{O}_{\mathrm{lg}}$ bond length of the intermediate was found to be $3.48 \AA$, indicating that the $\mathrm{C}-\mathrm{O}_{\mathrm{lg}}$ bond was completely broken and deformed, which facilitated the addition reaction 
of water molecules in the next step. The reaction energy barrier of the elimination step was $37.1 \mathrm{kcal} / \mathrm{mol}$, which was higher than that of the addition step of $33.2 \mathrm{kcal} / \mathrm{mol}$, so the first step was shown to be the rate-limiting step. TS2 is the transition state of the addition step. From the structure of TS2, it could be seen that the water molecule formed a bond with the alkyl-carbon, and the proton of the alkyl-carbon returned to the cyclobutane. The C-O nuc bond length was found to be $2.47 \AA$, and the $\mathrm{C}-\mathrm{H}_{\mathrm{lg}}$ bond length was $1.42 \AA$.

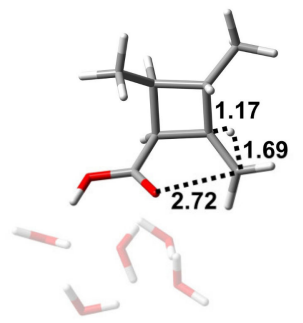

TS1

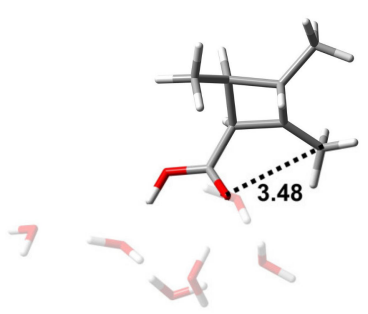

Int

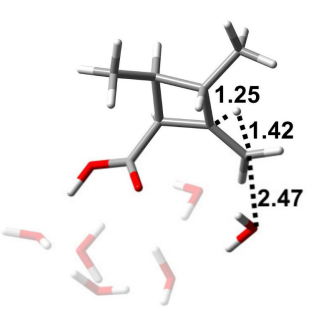

TS2

Figure 8. Structures of TS1, Int, and TS2 of the $\mathrm{A}_{\mathrm{AL}} 1$ reaction path of $\mathrm{CBL}+5 \mathrm{H}_{2} \mathrm{O}+\mathrm{H}_{3} \mathrm{O}^{+}$. The unit of distance is $\AA$.

\section{Conclusions}

Various mechanisms of a cyclobutane-fused lactone hydrolysis in alkaline and acidic conditions were studied using DFT-D3 and mixed implicit/explicit solvent models. This study indicates that it is highly possible for $\mathrm{CBL}$ to follow the $\mathrm{B}_{\mathrm{AC}} 2$ and $\mathrm{A}_{\mathrm{AC}} 2$ mechanisms in alkaline and acidic conditions, respectively. The $\mathrm{B}_{\mathrm{AC}} 2$ and $\mathrm{A}_{\mathrm{AC}} 2$ mechanisms are the two most important pathways in ester hydrolysis, and both of them are two-step reactions. We conducted a detailed discussion of the $\mathrm{B}_{\mathrm{AC}} 2$ mechanism, and the calculation results showed that adding an increasing number of explicit water molecules to the $\mathrm{B}_{\mathrm{AC}} 2$ reaction tightens the transition state geometries by introducing hydrogen-bonding interactions. When there was one water molecule or no water molecule in the model, activation free energies were remarkably lower than when more water molecules were added. Regardless of acidic or alkaline hydrolysis, the structures of the CBL hydrolysate remain unchanged, i.e., the initial "lactone group" remains cyclic after hydrolysis, which is beneficial to the reverse reaction (esterification reaction). These conclusions will help to guide future experiments and develop functional materials with degradability and stability.

Supplementary Materials: The following are available online: Figure S1: Structures of the transition state of intramolecular proton transfer along the $\mathrm{B}_{\mathrm{AC}} 2$ reaction path without $\mathrm{H}_{2} \mathrm{O}$ or with one $\mathrm{H}_{2} \mathrm{O}$ molecule. Figure S2: The results of intrinsic reaction path calculation of $\mathrm{CBL}$ along $\mathrm{B}_{\mathrm{AC}} 2$ reaction path with $5 \mathrm{H}_{2} \mathrm{O}$ molecules. Figure S3: The potential energy surface scan (PES) curves of deprotonation and protonation of $\mathrm{CBL}+6 \mathrm{H}_{2} \mathrm{O}+\mathrm{OH}^{-}$. Figure S4: The potential energy surface scan (PES) curves of acyl-oxygen cleavage of CBL $+5 \mathrm{H}_{2} \mathrm{O}+\mathrm{H}_{3} \mathrm{O}^{+}$. Table S1: Free energies of TS1, Int1, and TS2 relative to $\mathrm{R}$ along the $\mathrm{B}_{\mathrm{AC}} 2$ reaction path of $\gamma$-butyrolactone. Table S2: Free energies of TS1, Int1, and TS2 relative to $\mathrm{R}$ along the $\mathrm{A}_{\mathrm{AC}} 2$ reaction path of $\gamma$-butyrolactone. Table S3: Comparison of $\mathrm{C}$-O distances to the nucleophile $\left(\mathrm{C}-\mathrm{O}_{\text {nuc }}\right)$ and leaving group $\left(\mathrm{C}-\mathrm{O}_{\mathrm{lg}}\right)$ at TS1, Int, TS2, and $\mathrm{P}$ of the $\mathrm{B}_{\mathrm{AC}} 2$ reaction path of CBL, with 0-6 $\mathrm{H}_{2} \mathrm{O}$ molecules. Table S4: Comparison of dihedral angles (C-C-C-C) to the cyclobutane at $\mathrm{R}, \mathrm{TS} 1$, Int, TS2, and $\mathrm{P}$ of the $\mathrm{B}_{\mathrm{AC}} 2$ reaction path of $\mathrm{CBL}$, with $0-6 \mathrm{H}_{2} \mathrm{O}$ molecules. Cartesian coordinates and SCF energies of all optimized stationary points are provided.

Author Contributions: Conceptualization, Z.W.; methodology, Z.W. and H.M.; software, Z.W.; validation, Z.W.; formal analysis, Z.W.; investigation, Z.W.; writing-original draft preparation, Z.W.; writing-review and editing, Z.W. and H.M.; visualization, Z.W.; supervision, H.M.; project administration, H.M.; funding acquisition, H.M. All authors have read and agreed to the published version of the manuscript.

Funding: This research was funded by the National Natural Science Foundation of China (Grant No. 22073045) and the Fundamental Research Funds for the Central Universities. 
Institutional Review Board Statement: Not applicable.

Informed Consent Statement: Not applicable.

Data Availability Statement: The data presented in this study are available on request from the corresponding author.

Acknowledgments: Thanks to Yaping Wen and Luis Carlos Vasquez Cardenas for their corrections and suggestions.

Conflicts of Interest: The authors declare no conflict of interest.

\section{References}

1. Hsu, T.G.; Zhou, J.; Su, H.W.; Schrage, B.R.; Ziegler, C.J.; Wang, J. A polymer with “locked" degradability: Superior backbone stability and accessible degradability enabled by mechanophore installation. J. Am. Chem. Soc. 2020, 142, 2100-2104. [CrossRef] [PubMed]

2. Sure, R.; El Mahdali, M.; Plajer, A.; Deglmann, P. Towards a converged strategy for including microsolvation in reaction mechanism calculations. J. Comput. Aided Mol. Des. 2021, 35, 473-492. [CrossRef] [PubMed]

3. Gómez-Bombarelli, R.; Calle, E.; Casado, J. Mechanisms of lactone hydrolysis in neutral and alkaline conditions. J. Org. Chem. 2013, 78, 6868-6879. [CrossRef] [PubMed]

4. Gómez-Bombarelli, R.; Calle, E.; Casado, J. Mechanisms of lactone hydrolysis in acidic conditions. J. Org. Chem. 2013, 78, 6880-6889. [CrossRef]

5. Yan, Z.; Lian, J.; Li, M.; Meng, L.; Zhang, Y.; Ge, C.; Lu, J. Deeper insight into hydrolysis mechanisms of polyester/cotton blended fabrics for separation by explicit solvent models. Int. J. Biol. Macromol. 2020, 154, 596-605. [CrossRef]

6. Szeler, K.; Williams, N.H.; Hengge, A.C.; Kamerlin, S.C. Modeling the alkaline hydrolysis of diaryl sulfate diesters: A mechanistic study. J. Org. Chem. 2020, 85, 6489-6497. [CrossRef]

7. Duarte, F.; Åqvist, J.; Williams, N.H.; Kamerlin, S.C. Resolving apparent conflicts between theoretical and experimental models of phosphate monoester hydrolysis. J. Am. Chem. Soc. 2015, 137, 1081-1093. [CrossRef]

8. Skyner, R.E.; McDonagh, J.L.; Groom, C.R.; Mourik, T.; Mitchell, J.B.O. A review of methods for the calculation of solution free energies and the modelling of systems in solution. Phys. Chem. Chem. Phys. 2015, 17, 6174-6191. [CrossRef]

9. Dub, P.A.; Ikariya, T. Quantum chemical calculations with the inclusion of nonspecific and specific solvation: Asymmetric transfer hydrogenation with bifunctional ruthenium catalysts. J. Am. Chem. Soc. 2013, 135, 2604-2619. [CrossRef]

10. Dong, S.; Bi, S. The solvation effect on the rattling behaviour of the hydrated excess proton in water. Phys. Chem. Chem. Phys. 2019, 21, 22385-22389. [CrossRef]

11. Pliego, J.R.; Riveros, J.M. Hybrid discrete-continuum solvation methods. Wiley Interdiscip. Rev. Comput. Mol. Sci. 2020, 10, e1440. [CrossRef]

12. Gadre, S.R.; Yeole, S.D.; Sahu, N. Quantum chemical investigations on molecular clusters. Chem. Rev. 2014, 114, 12132-12173. [CrossRef]

13. Maldonado, A.M.; Hagiwara, S.; Choi, T.H.; Eckert, F.; Schwarz, K.; Sundararaman, R.; Otani, M.; Keith, J.A. Quantifying uncertainties in solvation procedures for modeling aqueous phase reaction mechanisms. J. Phys. Chem. A 2021, 125, 154-164. [CrossRef]

14. Ingold, C.K. Structure and Mechanism in Organic Chemistry, 2nd ed.; Cornell University Press: Ithaca, NY, USA, 1969; pp. 457-463.

15. Edenborough, M. Organic Reaction Mechanisms: A Step by Step Approach, 2nd ed.; CRC Press: London, UK, 1998; pp. 168-170.

16. Grimme, S.; Antony, J.; Ehrlich, S.; Krieg, H. A consistent and accurate ab initio parametrization of density functional dispersion correction (DFT-D) for the 94 elements H-Pu. J. Chem. Phys. 2010, 132, 154104. [CrossRef]

17. Frisch, M.J.; Trucks, G.W.; Schlegel, H.B.; Scuseria, G.E.; Robb, M.A.; Cheeseman, J.R.; Scalmani, G.; Barone, V.; Petersson, G.A.; Nakatsuji, H.; et al. Gaussian 16 Rev. A.03; Gaussian, Inc.: Wallingford, CT, USA, 2016.

18. Akbulatov, S.; Tian, Y.; Kapustin, E.; Boulatov, R. Model studies of the kinetics of ester hydrolysis under stretching force. Angew. Chem. Int. Ed. 2013, 125, 7130-7133. [CrossRef]

19. Marenich, A.V.; Cramer, C.J.; Truhlar, D.G. Universal solvation model based on solute electron density and on a continuum model of the solvent defined by the bulk dielectric constant and atomic surface tensions. J. Phys. Chem. B 2009, 113, 6378-6396. [CrossRef]

20. Tunon, I.; Rinaldi, D.; Ruiz-Ldpez, M.F.; Rivail, J.L. Hydroxide ion in liquid water: Structure, energetics, and proton transfer using a mixed discrete-continuum ab initio model. J. Phys. Chem. 1995, 99, 3798-3805. [CrossRef]

21. Pliego, J.R.; Riveros, J.M. The cluster-continuum model for the calculation of the solvation free energy of ionic species. J. Phys. Chem. A 2001, 105, 7241-7247. [CrossRef]

22. Kelly, C.P.; Cramer, C.J.; Truhlar, D.G. Adding explicit solvent molecules to continuum solvent calculations for the calculation of aqueous acid dissociation constants. J. Phys. Chem. A 2006, 110, 2493-2499. [CrossRef]

23. Pliego, J.R. Basic hydrolysis of formamide in aqueous solution: A reliable theoretical calculation of the activation free energy using the cluster-continuum model. Chem. Phys. 2004, 306, 273-280. [CrossRef] 
24. Ślebocka-Tilk, H.; Neverov, A.A.; Brown, R.S. Proton inventory study of the base-catalyzed hydrolysis of formamide. Consideration of the nucleophilic and general base mechanisms. J. Am. Chem. Soc. 2003, 125, 1851-1858. [CrossRef] [PubMed]

25. Xiong, Y.; Zhan, C.G. Theoretical studies of the transition-state structures and free energy barriers for base-catalyzed hydrolysis of amides. J. Phys. Chem. A 2006, 110, 1264-12652. [CrossRef] [PubMed]

26. Wang, B.; Cao, Z. Mechanism of acid-catalyzed hydrolysis of formamide from cluster-continuum model calculations: Concerted and stepwise pathway. J. Phys. Chem. A 2010, 114, 12918-12927. [CrossRef] [PubMed]

27. Catak, S.; Monard, G.; Aviyente, V.; Ruiz-López, M.F. Deamidation of asparagine residues: Direct hydrolysis versus succinimidemediated deamidation mechanisms. J. Phys. Chem. A 2009, 113, 1111-1120. [CrossRef]

28. Pan, B.; Ricci, M.S. Molecular mechanism of acid-catalyzed hydrolysis of peptide bonds using a model compound. J. Phys. Chem. B 2010, 114, 4389-4399. [CrossRef]

29. Kabanda, M.M.; Tran, Q.T.; Ebenso, E.E. A computational study of pyrazinamide: Tautomerism, acid-base properties, microsolvation effects and acid hydrolysis mechanism. Comput. Theor. Chem. 2014, 1046, 30-41. [CrossRef]

30. Petrović, D.; Szeler, K.; Kamerlin, S.C.L. Challenges and advances in the computational modeling of biological phosphate hydrolysis. Chem. Commun. 2018, 54, 3077-3089. [CrossRef]

31. Li, L.; Lelyveld, V.S.; Prywes, N.; Szostak, J.W. Experimental and computational evidence for a loose transition state in phosphoroimidazolide hydrolysis. J. Am. Chem. Soc. 2016, 138, 3986-3989. [CrossRef]

32. Duarte, F.; Barrozo, A.; Åqvist, J.; Williams, N.H.; Kamerlin, S.C.L. The competing mechanisms of phosphate monoester dianion hydrolysis. J. Am. Chem. Soc. 2016, 138, 10664-10673. [CrossRef]

33. Mora, J.R.; Kirby, A.J.; Nome, F. Theoretical study of the importance of the spectator groups on the hydrolysis of phosphate triesters. J. Org. Chem. 2012, 77, 7061-7070. [CrossRef]

34. Kamerlin, S.C.L.; Williams, N.H.; Warshel, A. Dineopentyl phosphate hydrolysis: Evidence for stepwise water attack. J. Org. Chem. 2008, 73, 6960-6969. [CrossRef]

35. Zhan, C.G.; Landry, D.W.; Ornstein, R.L. Energy barriers for alkaline hydrolysis of carboxylic acid esters in aqueous solution by reaction field calculations. J. Phys. Chem. A 2000, 104, 7672-7678. [CrossRef]

36. Xie, D.; Zhou, Y.; Xu, D.; Guo, H. Solvent effect on concertedness of the transition state in the hydrolysis of p-nitrophenyl acetate. Org. Lett. 2005, 7, 2093-2095. [CrossRef]

37. Pliego, J.R.; Riveros, J.M. A theoretical analysis of the free-energy profile of the different pathways in the alkaline hydrolysis of methyl formate in aqueous solution. Chem. Eur. J. 2002, 8, 1945-1953. [CrossRef]

38. Xu, T.; Chen, J.; Wang, Z.; Tang, W.; Xia, D.; Fu, Z.; Xie, H. Development of prediction models on base-catalyzed hydrolysis kinetics of phthalate esters with density functional theory calculation. Environ. Sci. Technol. 2019, 53, 5828-5837. [CrossRef]

39. Fukui, K. The path of chemical reactions-the IRC approach. Acc. Chem. Res. 1981, 14, 363-368. [CrossRef]

40. Tuñón, I.; Williams, I.H. The transition state and cognate concepts. Adv. Phys. Org. Chem. 2019, 53, $29-68$. 